\title{
EFFECTS OF RELATIVE EFFICIENCY AND INDUSTRIAL DIVERSITY ON PRODUCTION OF OLD INDUSTRIAL COMPLEX
}

\author{
MYOUNG SUB CHOI ${ }^{1} \&$ HWAN YONG PARK ${ }^{2}$ \\ ${ }^{1}$ Government Innovation \& Productivity Institute, The Catholic University of Korea, South Korea \\ ${ }^{2}$ Urban Planning, Gachon University of Korea, South Korea
}

\begin{abstract}
This study aimed to evaluate the effects of relative efficiency and industrial diversity of old industry complex on production. Cobb-Douglas production function was estimated with consideration of relative efficiency and inverse of Herfindahl-Hirschman Index for the 94 old industrial complexes during 2014-2017. The effects on production which would be varied by industrial complex types and location types were also considered in the production model. As a result, statistically significant positive effects on productivity in old industrial complex have been estimated regardless of not only types of industrial complex (national and general industrial complex) but also location type (capital and non-capital area). In contrast, diversity estimated has a negative impact on productivity, but it does not show statistical significance. Therefore, to activate old industrial complex, plans for increases of relative efficiency by operation cost reductions of businesses in industrial complex will be needed. And to diversify the industrial types in old industrial complex, plans should consider the types of industrial complex and location type. Industrial linkages among companies in old industrial complex should also be considered in the process of selecting business.

Keywords: relative efficiency, industry diversity, Herfindahl-Hirschman index, Cop-Douglass production function, deteriorated industrial complex
\end{abstract}

\section{INTRODUCTION}

The revitalization of old industrial complexes is important because they affect not only the growth of the industrial complex but also the regional economic development. In addition, there are national benefits in that the activation of an existing industrial complex can minimize social costs, compared to the development of a new industrial complex. The government has responded to the problem of aging industrial complexes and is trying to improve the competitiveness of aging industrial complexes by rebuilding industrial complexes, improving the structure and enacting special laws. On the other hand, there seems to be a lack of examination of the production side of the old industrial complexes or the industrial complexes itself. Regarding the existing industrial complexes, they still analyse the determinants of competitiveness, location, price and employment. It was not enough. Therefore, this study focuses on the relative efficiency and industry diversity among these determinants.

The relative efficiency of old industrial parks is an indicator of how efficiently they operate, which can determine whether efficient industrial parks can lead to increased production. The diversity of industries in old industrial parks puts a question on whether the concentration of industries within an industrial park on specific industries helps production or whether the composition of various industries has a positive effect on production.

Hence, this study examines how the relative efficiency of old industrial parks and the diversity of industries affect their production. This study is carried out as follows. Chapter 2 examines how relative efficiency and diversity relate to production and presents differences 
of the study. Chapter 3 describes the Cop-Douglas function used in the study, the relative efficiency and the analysis data to measure industry diversity. Chapter 4 illustrates the impact of relative efficiency and industry diversity on production, while Chapter 5 outlines the implications and limitations of research.

\section{LITERATURE REVIEW}

\subsection{Relative efficiency and relationship with production}

The relative efficiency measurement of industrial parks has been carried out in previous studies, mainly through data development analysis (DEA). Results from previous studies show relative efficiency differences in the size of the tenant companies, location characteristics, type of industrial complexes and operation period. And, to improve relative efficiency in the old industrial complex, they proposed to enhance operating rates, remodel aged facilities, increase external effects, and diversify industries [1-3]. However, previous studies have mainly focused on measuring the relative efficiency of industrial parks. In some studies, the determinant of relative efficiency was taken into account. Kim and Cho [2] measured relative efficiency through DEA for industrial park tenants and non-location enterprises, which were derived through the Tobit model.

Only a few studies take into account the approach to the effects of relative efficiency on production that are addressed in this study. Choi [4] analysed how the efficiency of the local government in the development region affected the growth of the local economy. The analysis showed that efficiency had a positive effect on economic growth. However, no approach has been made in terms of industrial parks. Therefore, this study will figure out the relationship between relative efficiency and production. As previously stated, relative efficiency is not necessarily a proportional relationship with production because it can be resolved in a way of reducing input costs in the same production scale [3].

\subsection{The relationship between industrial diversity and production}

The diversity of industries is related to the urban economy, and existing studies also explain the local economy, including its factors as an industrial structure or an urban economy. Byeon [5] analysed the effects of the integrated economy on the information and communication manufacturing industries in the Seoul metropolitan area and showed that the diversification of the industries had a negative effect on the aggregate. Mo and Kang [6] analysed the impact of regional industrial structures on the local economy. They found that industrial diversity has a negative effect on the national economy. But in terms of areas, the Seoul metropolitan area and Yeongnam region have a positive effect, and the Chungcheong and Jeolla provinces have a negative effect. In Park [7], for the entire manufacturing industry, the diversity of the industry was negative, but not statistically significant. However, in case of transport manufacturing, the effect was shown to be statistically negatively significant.

The existing studies show different effects of diversity and production depending on the analysis target, region and time. It comes on a background that there exists a limit to the assessment of how diversity in industries within industrial parks will affect production. For this reason, no research has been conducted only on industrial parks. In this aspect, this study is particularly different from existing research on the manufacturing industry field. 


\subsection{Difference in this study}

Previous studies have led to a number of measures of the relative efficiency of industrial parks, but have not been conducted on whether relative efficiency helps increase production. Even though the concept of relative efficiency is reviewed, it is difficult to determine in which direction the effects of relative efficiency on production will be in an old industrial park, since the effects of higher relative efficiency in an old industrial park can be achieved by reduced input costs or increased production.

In comparison, there has been relatively much progress regarding the impact of industrial diversity on production, while focus has been on regional aspects rather than on industrial complexes. However, the effects of diversity on the local economy are not consistent with codes and statistical significance, which vary by analysis target, region and time. Therefore, it is interesting to check out how diversity in the industry will affect production in the aged industrial parks subject to this study.

Therefore, this study needs to take a concrete approach to how relative efficiency and industry diversity affect the production of old industrial complexes. For this purpose, the analytical model includes two variables discussed earlier in the production function approach, which was primarily used in existing studies.

\section{FRAME OF ANALYSIS}

\subsection{Analysis method}

The Cobb-Douglass production function is applied to analyse the effects of the efficiency of old industrial parks and the diversity of industries on production. The Cobb-Douglas production function is an economic model that can analyse the impact of production elements on production or value added, as it has previously been mainly used as one of the models for explaining production factors, especially in manufacturing [8-11].

The following production functions are set as the basic model. Here, $Y, L, K$ and $A$ represent industrial park output, number of workers, capital stock and total component productivity, respectively. However, in this study, the site area was used as a proxy variable for the capital stock, because it is not provided by the statistics related to the industrial park. Considering these limitations, Kim and Choi [11] also applied the land area as a proxy variable for the capital stock in estimating the production function of the old industrial park.

$$
\mathrm{Y}=A L^{\alpha} K^{\beta}
$$

It is then assumed that total component productivity $(A)$ consists of Dea (relative efficiency) and Div (industrial diversity) and other $(B)$. Since the total element productivity reflects the remaining factors not included in single-element productivity measures, such as labour and capital, it is desirable to define relative efficiency and industry diversity as components of total element productivity in this study, which in turn affects production through changes in total element productivity.

$$
\mathrm{A}=B D e^{\gamma} D i v^{\delta}
$$

Combining the two formulas allows the final formula to be set as follows: the size of $\alpha+\beta$ means the economic level of scale and $\alpha+\beta>1$ means that the output will be greater than $1 \%$, 
when the input of labour and capital increases by $1 \%$, in which case the economy of scale will exist. Using the estimation results of the formula, it is possible to determine the level of economy of scale.

$$
\mathrm{Y}=B L^{\alpha} K^{\beta} \operatorname{Dea}^{\gamma} \operatorname{Div}^{\delta}
$$

However, Formula 3 is a nonlinear model, which requires linearization of functions to be estimated by means of logarithmic transformation [12].

$$
\ln Y=\ln B+\alpha \ln L+\beta \ln K+\gamma \ln D e a+\delta \ln D i v
$$

The relative efficiency index, one of the major independent variables, is derived from DEA. Previous studies have also estimated relative efficiency through DEA for industrial parks [1-3]. Efficiency in the DEA is defined as relative efficiency and is calculated between 0 and 1 because it represents the level of that Decision Making Unit (DMU) relative to the most efficient observation (DMU) [13]. In DEA, relative efficiency can be estimated separately on input and output basis from Charnes, Cooper and Rhodes (CCR) and Banker, Charnes and Cooper (BCC). This study is based on the BCC model on the output basis. The reason for applying the production approach in this paper is that developed industrial parks are easier to control production volume than inputs, and that $\mathrm{BCC}$ is more realistic than CCR that assume a constant return to scale [3].

The diversity of industries within old industrial parks uses the reciprocal of the HerfindahlHirschman index (HHI). The HHI has been used primarily to measure the diversity of the industrial structure at the urban and regional levels [14-16]. Therefore, it is also possible to apply it to the industrial parks. The HHI of old industrial parks ought to be the maximum value of 1 if all workers in the industrial park are concentrated in one industry, and the highest value will be $1 / n$ if the number of workers is equally distributed in $n$ industries. Therefore, the HHI is measured at a smaller value as the region's industrial structure becomes more diverse. The larger the HHI, the less diversity is interpreted. For the convenience, its reciprocal is used. Therefore, the larger the reciprocal value of the HHI, it can be interpreted as more diverse. This means that higher the diversity, the greater the output, if the estimated coefficients are positive.

$$
\frac{1}{H H I_{j}}=1 / \sum_{i=1}^{I}\left(\frac{E_{i j}}{E_{j}}\right)^{2}
$$

\subsection{Analysis data}

This study focuses on old industrial parks and targets 94 old industrial complexes derived from Park and Park [17]. The old industrial complex consists of 21 national industrial complexes and 73 general industrial complexes by type, while there are 30 metropolitan areas and 64 non-capital areas by location.

For the construction of models in this study, the production amount, site area, number of workers, relative efficiency index and the HHI are required. The basic data for estimating the production function model is based on the current status of the national industrial complex of the Korea Industrial Complex Management Corporation. The data provide the amount of production, land area and number of workers for each individual industrial complex. However, time span is extended to 2014-2017 to ensure statistical significance of the estimate. The production amount should be on a point-in-time basis in the production function model; therefore, the difference exists in value of the amount. The figure was adjusted to the base 
price in 2015 using the GDP deflator provided by the Bank of Korea's economic statistics system. The same approach is applied to DEA for the measurement of relative efficiency. The relative efficiency of this study is analysed as DMU for 94 individual aged industrial complexes, based on the BCC model which used site area and number of workers as input variables. Similar procedures for the analysis was used as in Choi [3].

Next, the HHI for measuring the diversity of industries is built using the raw data in individual industries of the Korea Industrial Complex Management Corporation between 2014 and 2017. The data provide key industries and the number of employees of individual companies in each industrial complex, so it can be applied to 94 aged industrial parks subject to this study. The HHI by industrial complex is based on the number of workers, not the number of companies. This is because the number of workers is more appropriate than the number of businesses to show diversity. Finally, the reciprocal of the derived HHI is included in the model. As of 2017, the correlation between the number of businesses, the number of workers and the amount of production in Korea's industrial parks was estimated, and the correlation between production and the number of employees (0.742) was larger than the correlation between production and number of businesses (0.570).

The basic statistics of the analysis data compiled are shown in the following table. The analysis data were divided into types of industrial parks (national and general industrial parks), location types (capital and non-capital areas) and two types of intersections (national and general industrial parks in capital areas, national and general industrial parks in noncapital areas). The results of production scale (production amount, area and number of workers) to determine the reliability of the construction data show that the national industrial complexes and non-capital areas are shown to be high. A similar pattern is also shown in the type of industrial complexes by location. Considering that national industrial parks are generally larger in terms of physical size than general industrial parks, it is believed that the data building in this study is reasonable in terms of the scale of production.

Next, the outcomes of relative efficiency are similar to those of size of production, in that the figures are high in national industrial parks and metropolitan areas. This is judged that relative efficiency of national industrial parks is likely be larger than that of general industrial parks because large enterprises or large companies with large production sizes are likely to move in. It is confirmed by the previous studies. Kim [18] showed the result that efficiency increases as a company grows in size and Noh [19] analysed that the relative efficiency of large companies is greater than that of small businesses.

However, the results of location type show the opposite results of production scale. This seems to be because older industrial parks located in capital areas have a higher effect of technological advancement compared to non-capital areas, as pointed out by Lee and Ahn [20]. The results of these elementary statistics are expected to have a positive impact on production by relative efficiency.

Finally, the results of industrial diversity are the opposite to the results of production scale, in general industrial parks and the capital areas, showing great diversity. A similar pattern was found by location type. The fact that national industrial parks are less diverse in industry than general industrial parks can be interpreted that national industrial parks are aggregated by similar industries on a division basis than general industrial parks. However, when subdivided into different types of industrial complexes by location type, the diversity of national industrial parks is high, and general industrial parks are high in capital areas. In view of this, it can be presumed that the impact of industrial diversity on production in the analysis of future production functions is basically negative, but the difference between location type and industrial complex type is likely to occur. 


\section{ANALYSIS RESULTS}

\subsection{Overall analysis}

Estimation has been made, based on production functions, to review how relative efficiency and diversity affect the production of old industrial parks. The overall analysis of 94 aged industrial parks covered by this study is shown in Table 2. It was analysed that the sum of the regression coefficients of area and number of workers was 1.066, achieving economy of scale. In other words, aged industrial parks would see a $1.066 \%$ increase in production if the production element (area and number of workers) increased by $1 \%$, showing a greater proportion of the increase in production to the increase in inputs, which is more than 1. Specifically, labour (the number of employees) has a greater impact than capital (the area). This is consistent with the results of existing studies on aged industrial park in certain areas, in which labour elasticity is greater than capital elasticity $[11,21]$.

Next, the results of relative efficiency and industry diversity, which are the main points of this study, are as follows: relative efficiency was analysed to have a statistically significant positive effect on the output. This means that relative efficiency affects not only the efficient operation of old industrial parks, but also the economic growth of old industrial parks. However, it is found that the diversity of the industry (the inverse of the HHI) has a statistically negative effect on the production of old industrial complexes. This can be interpreted as a decrease in the total output of old industrial complexes as industries in old industrial complexes are diversified. This is viewed to be due to the large diversity, in general industrial parks and capital areas, with relatively small output, as indicated in the basic statistics summarized in Table 1.

Finally, the results according to location type and industrial complex type are as follows. The regression coefficient of dummy variable for the capital areas was negative (-). This appears to be due to the larger production volume of non-capital areas rather than capital areas, given the 94 aged industrial parks under analysis (see Table 2). However, what is unique is that the code of general industrial parks was presumed to be (+). This means that the basic output of general industrial parks is greater than that of national industrial parks, when controlling the production factors (area and capital), relative efficiency and diversity of industries, which was not derived from the results of the basic statistics in Table 1. These results suggest that

Table 1: Basic statistics.

\begin{tabular}{|c|c|c|c|c|c|c|}
\hline & & $\begin{array}{l}\text { Production } \\
\text { amount (KRW } \\
100 \text { million) }\end{array}$ & $\begin{array}{l}\text { Area (thou- } \\
\text { sand } \mathrm{m}^{2} \text { ) }\end{array}$ & $\begin{array}{l}\text { Workers } \\
\text { (thousands) }\end{array}$ & $\begin{array}{l}\text { Relative } \\
\text { efficiency }\end{array}$ & $\begin{array}{l}\text { Herfindahl } \\
\text { reciprocal } \\
\text { number }\end{array}$ \\
\hline \multicolumn{2}{|l|}{ National } & 268,224 & 27.4 & 52.8 & 0.481 & 0.172 \\
\hline \multicolumn{2}{|l|}{ General } & 22,108 & 1.3 & 5.5 & 0.337 & 0.238 \\
\hline \multicolumn{2}{|c|}{ Capital areas } & 53,524 & 5.5 & 22.1 & 0.432 & 0.240 \\
\hline \multicolumn{2}{|c|}{ Non-capital areas } & 88,139 & 7.9 & 13.3 & 0.340 & 0.215 \\
\hline \multirow{2}{*}{$\begin{array}{l}\text { Capital } \\
\text { areas }\end{array}$} & National & 222,262 & 25.7 & 94.3 & 0.556 & 0.145 \\
\hline & General & 11,339 & 0.4 & 4.0 & 0.401 & 0.265 \\
\hline \multirow{2}{*}{$\begin{array}{l}\text { Non-capital } \\
\text { areas }\end{array}$} & National & 286,609 & 28.0 & 36.2 & 0.451 & 0.182 \\
\hline & General & 27,383 & 1.7 & 6.2 & 0.306 & 0.226 \\
\hline
\end{tabular}


Table 2: Full analysis results.

\begin{tabular}{lcccc}
\hline & Coefficient & Standard error & $t$ value & $p$ value \\
\hline (constant) & 6.776 & 0.180 & 37.71 & 0.0001 \\
ln area & 0.427 & 0.025 & 17.05 & 0.0001 \\
ln number of workers & 0.639 & 0.022 & 28.53 & 0.0001 \\
ln DEA & 0.816 & 0.027 & 30.76 & 0.0001 \\
ln Herfindahl reciprocal & -0.071 & 0.040 & -1.76 & 0.0790 \\
Dummy for metropolitan & -0.0178 & 0.052 & -3.42 & 0.0007 \\
Dummy for general parks & 0.282 & 0.067 & 4.19 & 0.0001 \\
Modified R & 0.967 & & & \\
\hline
\end{tabular}

Note: The reference group for general industrial park is the national industrial park and the reference group for metropolitan area is the non-capital area.

the production function of aged industrial parks should be estimated separately by the type of industrial park. This suggestion comes from one of the basic assumptions in estimating the overall production function that each of the independent variables has the same effect on production for each type of industrial complex. In particular, if the size of the capital elasticity and labour elasticity embodied in the production component is reversed by the type of industrial complex (capital elasticity), the analysis may be difficult to interpret, based on the assumption that its influence is the same for each type of industrial complex (such as labour elasticity and labour elasticity). Therefore, it is necessary to estimate the production functions separately by type of industrial park for this aspect.

\subsection{Analysis results by type}

As noted earlier in this section, two types of approaches are taken to examine whether the production factors, relative efficiency and diversity affect production by type of industrial complex. It comes from the background that using industrial park type and location type as a dummy in the overall model would assume that the slope of the remaining independent variables would be the same except for the dummy variables. It may not be right in some sense. Therefore, it is more appropriate to estimate separately for each type, when there is a strong assurance in that there are differences in slope by type of industrial complex and location.

Type 1 is the type of industrial complex, which is divided into national industrial parks and general industrial parks. This is because of the different types of industrial parks, including the size of complexes and tenant companies. Considering another possibility that there may be also differences by type of industrial location, they are divided into four groups: national industrial and general industrial parks in the capital area and national and general industrial parks in the non-capital area. Of course, it can be divided into location types. However, because location types are mixed with each location, the results vary depending on which type of industrial park is included. Therefore, it is decided not to include the analysis in this study because it is difficult to achieve consistency when they are classified by location type.

The relationship between the production factors and the production (see Table 3) showed different results in the influence and order by type of industrial parks. In other words, the overall 
analysis showed that labour elasticity is greater than capital elasticity. However, according to the type of industrial complex, the national industrial park showed capital elasticity is greater than labour elasticity, and the general industrial park showed that labour elasticity is greater than capital elasticity. It seems likely that the results are affected by the size of general industrial parks, which account for the majority (77.7\%) of the 94 old industrial complexes in this analysis. Therefore, it is reasonable to make estimation by the type of industrial park separately in estimating the production function of industrial parks. In addition, there are also differences in the number of production elements when subdividing into location types. But the ranking was found to be the same (see Table 4). In all types of industrial complexes, the capital areas were more resilient than non-capital areas. Therefore, it seems that national industrial parks will need strategies for promoting capital, while general industrial parks will need strategies for promoting employment. Within the same type, complexes in capital areas need capital-oriented strategies and complexes in non-capital areas will need promoting employment-oriented activities.

Next, economy of scale is shown to be different depending on industrial complex type rather than location type. In terms of economy of scale, general industrial parks show economy of scale, while national industrial parks show dis-economy of scale (see Table 3 ). The same is true for each location type (see Table 4). Therefore, the type of negative economy of scale would require measures to increase output (production) rather than input (capital or employment), while the type of economy of scale would need to seek measures to boost input size rather than production.

In addition, relative efficiency shows positive statistical significance, as in the overall analysis, even though type is subdivided. However, the size of relative efficiency in national industrial parks is larger than that in general industrial parks, and the figures of non-capital areas are higher than those of the capital areas (see Table 3). When it is subdivided by type, the size of relative efficiency was shown in the order of national industrial parks in the noncapital area, national industrial parks in capital areas, general industrial parks in the noncapital areas and general industrial parks in the capital areas (see Table 4). Therefore, it is necessary to focus on general industrial parks and to enable them to achieve efficient operation

Table 3: Production function estimation result (type 1).

\begin{tabular}{|c|c|c|c|c|c|c|c|c|}
\hline & \multicolumn{4}{|c|}{ National industrial park } & \multicolumn{4}{|c|}{ General industrial park } \\
\hline & $\overline{\text { Coefficient }}$ & $\begin{array}{l}\text { Standard } \\
\text { error }\end{array}$ & $t$ value & $p$ value & $\overline{\text { Coefficient }}$ & $\begin{array}{l}\text { Standard } \\
\text { error }\end{array}$ & $t$ value & $p$ value \\
\hline (constant) & 9.919 & 0.329 & 30.17 & 0.0001 & 6.775 & 0.155 & 43.62 & 0.0001 \\
\hline ln area & 0.467 & 0.021 & 22.02 & 0.0001 & 0.343 & 0.042 & 8.23 & 0.0001 \\
\hline $\begin{array}{l}\text { ln number of } \\
\text { workers }\end{array}$ & 0.380 & 0.029 & 12.93 & 0.0001 & 0.736 & 0.033 & 22.02 & 0.0001 \\
\hline $\ln$ DEA & 1.139 & 0.037 & 30.90 & 0.0001 & 0.783 & 0.031 & 25.40 & 0.0001 \\
\hline $\begin{array}{l}\text { In Herfindahl } \\
\text { reciprocal }\end{array}$ & -0.371 & 0.093 & -4.00 & 0.0001 & -0.058 & 0.043 & -1.33 & 0.1830 \\
\hline $\begin{array}{l}\text { Dummy for } \\
\text { capital }\end{array}$ & -0.207 & 0.066 & -3.16 & 0.0022 & -0.149 & 0.064 & -2.32 & 0.0212 \\
\hline Modified $R^{2}$ & & 0.986 & & & & 0.953 & & \\
\hline
\end{tabular}

Note 1: The reference group in the Seoul metropolitan area is the non-capital area. 
of tenant businesses through basic cost-saving strategies and improving the infrastructure of old industrial parks [22-24].

Finally, industry diversity (HHI reciprocal) in type 1 indicates that national industrial parks are statistically significant and robust, whereas general industrial parks have shown a negative sign but have not secured statistical significance (see Table 3).

If the types are further subdivided, statistical significance is not ensured in national complexes in capital areas and general complexes in non-capital areas (see Table 4). This is believed to have occurred due to the small difference in the value of the diversity index of national complexes in the capital areas and general complexes in non-capital areas. However, other types of industrial parks (general industrial parks in the capital areas and national industrial parks in non-capital areas) showed that the higher the industrial diversity in old industrial complexes, the more negative effects on production. This can be interpreted as a kind of integrated economy in which the aggregation of a particular group of industries has more influence on production than the diverse group of industries. However, it was found that for general industrial parks in non-capital areas, the regression coefficients for the diversity of industries are positive or not statistically significant. Therefore, when it comes to the distribution of industries in the regeneration of old industrial complexes in the future, it is deemed to be necessary to consider the linkages with major industries rather than seeking diversity.

Table 4: Production function estimation result (type 2).

\begin{tabular}{|c|c|c|c|c|c|c|c|c|c|}
\hline & & \multicolumn{4}{|c|}{ National industrial park } & \multicolumn{4}{|c|}{ General industrial park } \\
\hline & & $\begin{array}{l}\text { Coef- } \\
\text { ficient }\end{array}$ & $\begin{array}{l}\text { Standard } \\
\text { error }\end{array}$ & $t$ value & $p$ value & Coefficient & $\begin{array}{l}\text { Standard } \\
\text { error }\end{array}$ & $t$ value & $p$ value \\
\hline \multirow{6}{*}{ 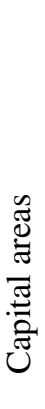 } & (constant) & 10.571 & 1.342 & 7.88 & 0.0001 & 6.230 & 0.232 & 26.86 & 0.0001 \\
\hline & ln area & 0.509 & 0.077 & 6.59 & 0.0001 & 0.514 & 0.089 & 5.75 & 0.0001 \\
\hline & $\begin{array}{l}\text { ln number of } \\
\text { workers }\end{array}$ & 0.214 & 0.092 & 2.34 & 0.0305 & 0.684 & 0.071 & 9.64 & 0.0001 \\
\hline & $\ln \mathrm{DEA}$ & 1.019 & 0.217 & 4.69 & 0.0002 & 0.587 & 0.066 & 8.94 & 0.0001 \\
\hline & $\begin{array}{l}\text { ln Herfindahl } \\
\text { reciprocal }\end{array}$ & -0.098 & 0.574 & -0.17 & 0.8667 & -0.312 & 0.084 & -3.71 & 0.0004 \\
\hline & Modified $R^{2}$ & \multicolumn{4}{|c|}{0.977} & \multicolumn{4}{|c|}{0.929} \\
\hline \multirow{6}{*}{ 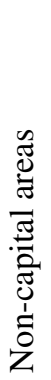 } & (constant) & 9.084 & 0.366 & 24.85 & 0.0001 & 7.204 & 0.173 & 41.54 & 0.0001 \\
\hline & $\ln$ area & 0.489 & 0.024 & 20.41 & 0.0001 & 0.281 & 0.042 & 6.72 & 0.0001 \\
\hline & $\begin{array}{l}\text { ln number of } \\
\text { workers }\end{array}$ & 0.438 & 0.030 & 14.80 & 0.0001 & 0.730 & 0.034 & 21.53 & 0.0001 \\
\hline & ln DEA & 1.088 & 0.036 & 30.35 & 0.0001 & 0.864 & 0.032 & 26.69 & 0.0001 \\
\hline & $\begin{array}{l}\text { In Herfindahl } \\
\text { reciprocal }\end{array}$ & -0.375 & 0.086 & -4.35 & 0.0001 & 0.041 & 0.046 & 0.89 & 0.3721 \\
\hline & Modified $R^{2}$ & \multicolumn{4}{|c|}{0.990} & \multicolumn{4}{|c|}{0.966} \\
\hline
\end{tabular}




\section{CONCLUSIONS AND IMPLICATIONS}

This study examined how the relative efficiency and diversity of old industrial parks really affect the production. For this purpose, the study used the industrial park status of the Korea Industrial Complex Corporation and raw data of individual industries as of 2014-2017, based on 94 aged industrial complexes to construct the analysis data. The model is estimated, including relative efficiency and the HHI reciprocal, using the basic model. However, it was approached separately, assuming that the effects of industrial complexes and location types would be different.

The analysis results and implications are as follows. First, the production elements of old industrial parks showed different influence on production by the type of industrial complexes. National industrial parks had a greater influence on the determination of production by capital rather than labour, while general industrial parks had higher contribution to the production by labour than capital. Therefore, it seems that national industrial parks will need promoting capital, while general industrial parks will need promoting employment. Within the same type, capital areas need capital-oriented strategies while non-capital areas will need promoting employment-oriented activities.

Second, it was analysed that national industrial parks enjoy dis-economy of scale and general industrial parks enjoy economy of scale. Therefore, negative economy of scale would require measures to increase output (production) rather than input (capital or employment), while economy of scale would need to seek measures to boost input size rather than production.

Third, the relative efficiency of old industrial parks has a statistically (+) significant effect on production regardless of the type of industrial parks (national and general industrial parks) and the type of locations (capital and non-capital areas). Therefore, the strategies for improving efficiency for old industrial complexes are deemed to have a positive impact on production. In the practical field, it is necessary to take measures to revitalize old industrial parks for the enhancement of relative efficiency by reducing costs of companies operating in industrial complexes. The existing research also suggested measures to secure operating rates, remodel old facilities, increase external effects, diversify industries and improve internal management inefficiency, so the focus should be on this. One of the other ways to reduce costs at the level of old industrial parks is to improve infrastructure. For this reason, national budgets for the regeneration of old industrial complexes should be injected [22-24].

Fourth, the diversity of old industrial parks has basically had negative effects on production as opposed to the result of relative efficiency, while the statistical significance is not secured in national industrial parks in capital areas and general industrial parks in the non-capital areas. The result is viewed to be due to the lack of close examination of the industrial park's connection with the industry when selecting the tenant companies. In particular, closer approach is required, in terms of the diversity of industries in old industrial parks, including industrial links with those that move into the industrial parks in selecting of additional businesses. Therefore, it is necessary to be cautious about strategies to diversify the industry in reviving old industrial complexes. In reality, there is a limit that it is very hard to reorganize the industries of old industrial parks that have already moved in and are in operation. In spite of the problems, it is necessary to introduce highly efficient industrial groups within aged industrial parks or those in the surrounding areas. The outcomes of industrial diversity in this study can be regarded as the diversity in manufacturing industries, since the figures were measured in the middle class of industrial classification for companies in industrial parks. However, it should be noted that the results of this study may be used cautiously, since the recent development of industrial complex tends to contain a mixture of manufacturing and service industries together. 
The limitations of this study also exist as always. First of all, inclusion of only the 94 industrial parks in this study is the main limitation so that constrains generalization of the outcomes of relationship among relative efficiency, industry diversity and production. Hence, this research product cannot be interpreted as the nation's entire industrial complex. Access to the data in all industrial parks is necessary for future generalizations, even though it is not easy since it takes a lot of time to organize the related data. Another limitation of the research is that it is assumed that each old industrial complex is a single group. If it is possible, more detailed analysis could be made using detailed information on the companies in each old industrial complex. In spite of all the limitations, we believe that this study is meaningful in attempting to determine the impact of relative efficiency and diversity on old industrial parks that were not covered by previous research.

\section{ACKNOWLEDGEMENTS}

This study was conducted with the support of the Ministry of Land, Infrastructure and Transport/the National Institute of Land, Infrastructure and Transport (Task No. 19AUDPB119346-04).

\section{REFERENCES}

[1] Ahn, Y.J. \& Lee, M.H., Comparative analyses of efficiency indices in the old industries complex applying data envelopment analysis (DEA) methods. Journal of The Korean Regional Development Association, 27(2), pp. 219-242, 2015.

[2] Kim, Y.D. \& Cho, J.M., A study on the efficiency analysis of industrial complex firms and non-industrial complex firms. Productivity Review, 31(4), pp. 159-185, 2017.

[3] Choi, M.S., Jang, S.I. \& Park, H.Y., Analysis on the relative efficiency of industrial complexes by type based on the DEA model. Korea Real Estate Review, 28(3), pp. 3752, 2018.

[4] Choi, J.Y., The effect of fiscal decentralization on economic growth in Korea: focused on production efficiency. Korean Public Administration Review, 49(3), pp. 161-191, 2015.

[5] Byeon, S.I., Analysis on socioeconomic agglomeration and spatial effect of the ICT manufacture industry in Seoul metropolitan area. GRI Review, 13(3), pp. 241-264, 2011.

[6] Mo, Y.M. \& Kang, M.H., A study on the effect of industrial structure by district in the local economy. Journal of Korea Regional Economics, 13(1), pp. 81-100, 2015.

[7] Park, S.H., Static and dynamic agglomeration economies in Korea. Journal of Korea Regional Economics, 13(1), pp. 81-100, 2015.

[8] Kim, Y.S., A study on the determinants of total factor productivity in Korea's regional manufacturing industry. Journal of Korea Planning Association, 38(5), pp. 199-212, 2003.

[9] Lee, Y.S., Metro cities' and provinces' total factor productivity and its determinants in Korea. The Korea Spatial Planning Review, 58, pp. 39-53, 2008.

[10] Park, D.Y., Seo, B.J. \& Jung, C.M., The effect of manufacturing firms' spatial distribution on the productivity of manufacturing industries in SMA. Journal of Korea Planning Association, 44(6), pp. 147-160, 2009.

[11] Kim, J.H. \& Choi, M.S., Economic benefit of renovating deteriorated industrial districts: production function approach. Journal of the Korea Real Estate Analysts Association, 23(4), pp. 53-63, 2017. 
[12] Gujarati, D.N. \& Porter, D.C., Basic Econometrics, 5th ed., McGraw-Hill International Edition, 2009.

[13] Lee, J.D. \& Oh, D.H., Theory of the Efficiency Analysis, Seoul: Jiphil Media, 2012.

[14] Ryu, S.Y. \& Yoon, S.M., Industrial diversification of the wide-economic zones and unemployment rate. Journal of the Korean Regional Science Association, 23(3), pp. 27-43, 2007.

[15] Ryu, S.Y., Choi, K.H., Ko, S.H. \& Yoon, S.M., The impact of industrial diversity to unemployment and employment instability: An analysis of regional economy using panel regression model. Journal of the Economic Geographical Society of Korea, 17(1), pp. 129-146, 2014.

[16] Moon, D.J. \& Hong, J.H., A study on the difference of industrial diversification's impact on local economic growth by city size and location. The Korean Journal of Local Government Studies, 19(3), pp. 125-152, 2015.

[17] Park, H.Y. \& Park, J.H., Analysis of the typology and factors affecting the decline in old industrial parks. Korea Real Estate Review, 27(4), pp. 7-20, 2017.

[18] Kim, Y.Y., Efficiency analysis of resident companies in industrial cluster complex. Journal of Economics Studies, 26(4), pp. 157-181, 2008.

[19] Lho, S.W., Analysis on the efficiency and productivity for machinery firms located at Changwon using DEA and Malmquist method. Journal of Economics Studies, 32(4), pp. 237-260, 2014.

[20] Lee, Y. \& Ahn, Y.H., Analysing efficiency of the selected national industrial complexes in Korea using DEA and Malmquist productivity index. Journal of The Korean Regional Development Association, 23(5), pp. 95-118, 2011.

[21] Kim, S.H., Choi, M.S. \& Kim, E.J., Temporal spatial externalities on agglomeration economy of manufacturing : estimation of spatial SUR by using 3SLS. Journal of the Economic Geographical Society of Korea, 10(4), pp. 414-426, 2007.

[22] Korea Development Institute, Daegu 3rd Industrial Complex Regeneration Project, $2011 \mathrm{a}$.

[23] Korea Development Institute, Daejeon Industrial Complex Regeneration Project, $2011 b$.

[24] Korea Development Institute, The West Daegu Industrial Complex Regeneration Project, 2011c. 